\title{
Article
}

\section{Cn-AMP2 from green coconut water is an anionic anticancer peptide}

Prabhu, Saurabh, Dennison, Sarah Rachel, Mura, Manuela, Lea, Robert William, Snape, Timothy James and Harris, Frederick

Available at http://clok.uclan.ac.uk/11695/

Prabhu, Saurabh, Dennison, Sarah Rachel ORCID: 0000-0003-4863-9607, Mura, Manuela ORCID: 0000-0002-3913-7595, Lea, Robert William, Snape, Timothy James ORCID: 0000-0003-2766-4491 and Harris, Frederick (2014) CnAMP2 from green coconut water is an anionic anticancer peptide. Journal of Peptide Science, 20 (12). pp. 909-915. ISSN 1075-2617

It is advisable to refer to the publisher's version if you intend to cite from the work. http://dx.doi.org/10.1002/psc.2684

For more information about UCLan's research in this area go to http://www.uclan.ac.uk/researchgroups/ and search for < name of research Group>.

For information about Research generally at UCLan please go to http://www.uclan.ac.uk/research/

All outputs in CLoK are protected by Intellectual Property Rights law, including Copyright law. Copyright, IPR and Moral Rights for the works on this site are retained by the individual authors and/or other copyright owners. Terms and conditions for use of this material are defined in the policies page.

\section{CLoK}

Central Lancashire online Knowledge www.clok.uclan.ac.uk

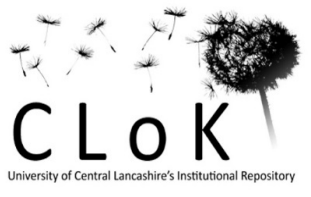


Published : Prabhu, S, Dennison SR, Mura M, Lea RW, Snape TJ and Harris F (2014) Cn-AMP2 from green coconut water is an anionic anticancer peptide. Journal of Peptide Science Volume 20, Issue 12, pages 909915, DOI: 10.1002/psc.2684

\section{Cn-AMP2 from green coconut water is an anionic anticancer peptide}

Saurabh Prabhu ${ }^{1}$, Sarah R. Dennison ${ }^{1}$, Manuela Mura ${ }^{2}$, Robert W. Lea ${ }^{1}$, Timothy J. Snape ${ }^{1}$ and Frederick Harris ${ }^{3 *}$,

${ }^{1}$ School of Pharmacy and Biomedical Sciences, University of Central Lancashire Preston, PR1 2HE, UK

${ }^{2}$ School of Computing Engineering and Physical Science, University of Central Lancashire, Preston, PR1 2HE, UK.

${ }^{3}$ School of Forensic and Investigative Science, University of Central Lancashire Preston, PR1 2HE, UK

*Corresponding author: Frederick Harris (fharris1@uclan.ac.uk) 


\begin{abstract}
Globally, death due to cancers is likely to rise to over 20 million by 2030, which has created an urgent need for novel approaches to anticancer therapies such as the development of host defence peptides. Cn-AMP2 (TESYFVFSVGM), an anionic host defence peptide from green coconut water of the plant, Cocos nucifera, and showed anti-proliferative activity against the $1321 \mathrm{~N} 1$ and U87MG human glioma cell lines with $\mathrm{IC}_{50}$ values of 1.25 and $1.85 \mathrm{mM}$ respectively. The membrane interactive form of the peptide was found to be an extended conformation, which primarily included $\beta$-type structures (levels $>45 \%$ ) and random coil architecture (levels $>45 \%$ ). Based on these and other data, it is suggested that the short anionic N-terminal sequence (TES) of Cn-AMP2 interacts with positively charged moieties in the cancer cell membrane. Concomitantly, the long hydrophobic C-terminal sequence (YFVFSVGM) of the peptide penetrates the membrane core region, thereby driving the translocation of Cn-AMP2 across the cancer cell membrane to attack intracellular targets and induce anti-proliferative mechanisms. This work is the first to demonstrate that AHDPs have activity against human glioblastoma, which potentially provides an untapped source of lead compounds for development as novel agents in the treatment of these and other cancers.
\end{abstract}

Running head: $\mathrm{Cn}$-AMP2 is an anionic anticancer peptide

Key words: Cn-AMP2, anticancer, human glioblastoma, 1321N1 and U87MG cell lines 


\section{Introduction}

Globally, cancer is now one of the leading causes of death which claimed lives at an annual rate of over 12.7 million in 2008 and is predicted to rise to over 20 million by 2030, [1], which has created an urgent need for novel approaches to anticancer therapies [2-4]. In response, there has been a move to develop anticancer strategies that are based on compounds from natural sources [5-8], including host defence peptides (HDPs) [9-11]. These peptides are multi-functional components of innate immune systems across the eukaryotic kingdom [12, 13] that show a potent ability to kill a wide variety of cancer cells $[9,11]$ and microbes [12, 14]. The vast majority of HDPs are cationic (CHDPs) [15, 16], which underpins their ability to discriminate against the membranes of healthy mammalian cells, which possess no overall charge, and target the membranes of microbial and cancer cell, which possess a net anionic charge $[9,11,12,14]$. Numerous studies have shown that membrane interaction is fundamental to the antimicrobial and anticancer activity of CHDPs and that in both cases, these interactions involve generally similar mechanisms [17]. In some instances, these mechanisms involve the translocation of these peptides across the plasma membranes of target cells to attack intracellular targets such as bacterial DNA [18, 19] or cancer cell mitochondria [20, 21]. However, most usually, the antimicrobial and anticancer mechanisms used by CHDPs involve direct attack on the membranes of target cells themselves, which can lead to death of the host cell via a variety of membranolytic processes that involve lipid perturbation and permeabilisation of the bilayer. $[9,11,12,14]$. A number of major models have been proposed to describe these processes such as the carpet mechanism and the toroidal pore model [17] with more recent examples, including; the tilted peptide mechanism [22] and amyloid-mediated mechanisms [23]. 
It is generally believed that the relatively non-specific nature of the processes involved in the antimicrobial and anticancer action of CHDPs renders it unlikely that resistance to this action can be acquired by microbes $[12,14]$ and cancer cells $[9,11]$. In the fight against rising global levels of cancer [24] and microbial infections [25, 26], this gives CHDPs a major advantage over conventional antibiotics and anticancer compounds, which show declining efficacy largely due to the increasing occurrence of multi-drug resistance in both microbial [27] and cancer cells [28]. In response, the therapeutic potential of CHDPs has been intensively investigated with the result that a number of these peptides are either in late-stage clinical trials or medical use as antimicrobial agents [29, 30] whilst most recently, the neutraceutical protein, lactoferrin, was patented as an anticancer agent [31] and in clinical trials, was shown to reduce the risk of colon carcinogenesis [32]. It has been predicted that many more CHDPs will soon advance to the stage of clinical trials as anticancer agents in the light of recent research progress [20, 21]. Nonetheless, in addition to CHDPs, anionic HDPs (AHDPs) have been increasingly recognised as an integral and important part of the innate immune system and thereby as a potential source of antimicrobial agents with novel mechanisms of action [33, 34]. There have been very few studies on the anticancer activity of AHDPs [35] and here, we have investigated the anticancer ability of Cn-AMP2 (TESYFVFSVGM), which is an AHDP from green coconut water with broad range antibacterial activity [36], against the human glioma cell lines, 1321N1 and U87MG. 


\section{Materials and Methods}

\section{Reagents}

Cn-AMP2 [36] was supplied by Pepceuticals (UK), produced by solid phase synthesis and purified by HPLC to greater than 99\%, which was confirmed by MALDI mass spectrometry. The peptide was stored as a stock solution of $3 \mathrm{mM}$ in dimethylsulphoxide (DMSO; $2 \% \mathrm{v} / \mathrm{v}$ ) at $-20^{\circ} \mathrm{C}$. All phospholipids were supplied by Avanti Polar Lipids (USA). SVGp12, a noncancerous foetal glial cell line, along with the human glioma cell lines 1321N1 (grade II) and U87MG (grade IV) were obtained from the European Collection of Cell Cultures, UK. Cisplatin was purchased from Sigma-Aldrich (UK).

Growth conditions for cancer cell lines

The SVGp12 cell line was maintained in Essential Minimum Eagle Medium (EMEM) supplemented with 2.5\% (v/v) FBS, 2 mM L-glutamine, $1 \mathrm{mM}$ sodium pyruvate and 1\% (v/v) non-essential amino acids (NEAA) (Lonza, UK). The 1321N1 and U87MG cell lines were maintained in Dulbeccos’s Modified Eagle’s Medium (DMEM) supplemented with 2.5\% (v/v) foetal bovine serum (FBS) and 2 mM L-glutamine (Lonza, UK). Each of these cell lines was maintained in a $37{ }^{\circ} \mathrm{C}$ humidified incubator supplied with $5 \% \mathrm{CO}_{2}$, all as previously described [37]. 
The effect of Cn-AMP2 on cell lines

The SVGp12 cell line was grown as described above, trypsinised and seeded in 96-well microtitre plates (Sarstedt, UK) such that wells contained a cell density of 4500 cells / $200 \mu$ l. in EMEM with an FBS concentration of 2.5\% (v/v). The 1321N1 and U87MG cell lines were similarly cultured except that wells contained DMEM with an FBS concentration of 2.5\% (v/v) and were seeded to give rise to cell densities of 4000 cells / $200 \mu \mathrm{l}$ and 3500 cells / $200 \mu \mathrm{l}$ respectively, all as previously described [37]. The following day when the cells were circa $60 \%$ confluent, Cn-AMP2 (final concentration varying between $0.25 \mathrm{mM}$ and $2.0 \mathrm{mM}$ ) was added to wells and the plates left to incubate for $72 \mathrm{~h}$. After this period of incubation, the membrane integrity (a) and viability (b) of these peptide-treated cells was ascertained:

(a) The membrane integrity of the SVGp12, 1321N1 and U87MG cells was examined either by recording images using an inverted microscope (Leica Microsystems, UK) or utilising the Trypan blue exclusion test (Sigma Aldrich, UK) according to manufacturer's instructions. Essentially, $10 \mu \mathrm{l}$ of Trypan Blue Dye was added to wells under investigation and the cells in these wells then observed under a microscope to identify Trypan blue staining, which is indicative of cell membrane lysis. As controls, these experiments were repeated in the absence of the peptide and, in all cases, experiments were performed in quadruplicate.

(b) The viability of cell lines was determined using the CellTiter 96® AQueous One Solution Cell Proliferation Assay (Promega, UK; MTS assay [38]) according to manufacturer’s instructions. Essentially, $20 \mu \mathrm{l}$ of pre-warmed MTS reagent was added to wells under investigation and the plates incubated at $37^{\circ} \mathrm{C}$ in a humidified incubator supplied with $5 \% \mathrm{CO}_{2}$ for $60 \mathrm{~min}$. At the end of this time, the absorbance of each well was recorded at $490 \mathrm{~nm}$ using a Tecan GENios Pro ${ }^{\circledR}$ microplate reader and used to determine \% cell viability. As controls, these experiments were repeated in the absence of the peptide and, in all cases, experiments were performed in quadruplicate. Non-linear regression analysis was used to yield the 
concentration of $C n$-AMP2 that inhibited $50 \%$ of cancer cell growth (IC50) when compared to untreated controls.

Figure 1. The effect of $\mathrm{Cn}$-AMP2 on the viability of cell lines

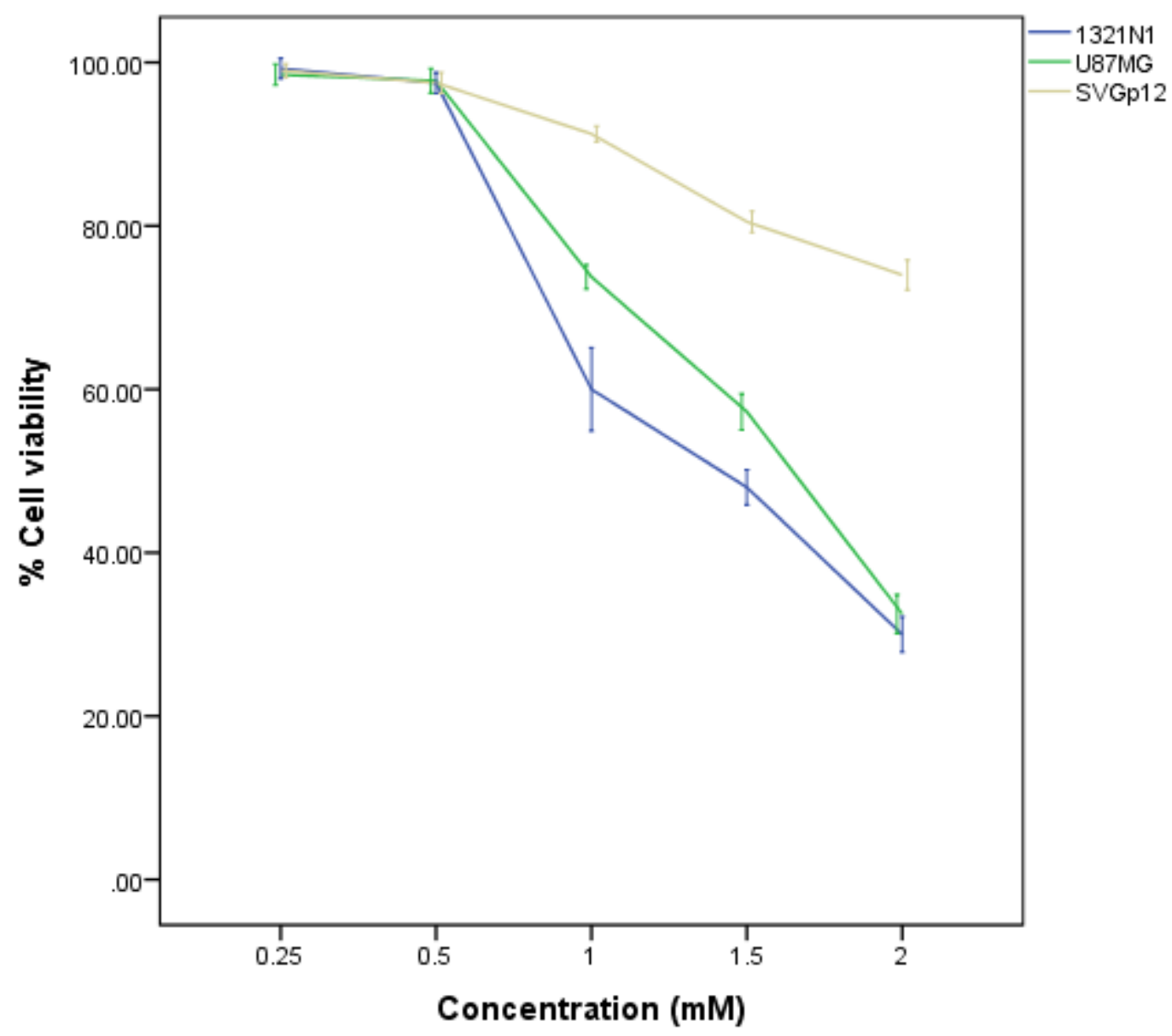

Figure 1 shows the effect of $C n$-AMP2 on the viability of cell lines when incubated as described above. Increasing concentrations of the peptide led to progressively larger reductions in the viability the human glioma cell lines, 1321N1 and U87MG, until at a Cn-AMP2 concentration $2.0 \mathrm{mM}$, these reductions were circa $70 \%$ as compared to controls. In contrast, at the same peptide concentration, Cn-AMP2 induced reductions in the viability of the non-cancerous, human glial cell-line, SVGp12, of circa $25 \%$ as compared to controls. Cell viability was determined by the MTS assay as described above and each data entry was the mean of 4 repeats and the error bars represent \pm the standard deviation. Regression analysis of these data entries yielded IC 50 values for $C n$-AMP2 that were $1.25 \mathrm{mM}$ for the $1321 \mathrm{~N} 1$ cell line and $1.85 \mathrm{mM}$ for U87MG cell line. 
Sequence analysis and molecular modelling of Cn-AMP2

The primary structure of Cn-AMP2, TESYFVFSVGM, was obtained from [36] and the potential of the peptide to adopt membrane interactive $\alpha$-helical structure determined by hydrophobic moment plot analysis. This methodology uses the mean hydrophobic moment, < $\mu \mathrm{H}>$, to measure the structured partitioning of hydrophobic and hydrophilic amino acid residues in a regular repeat structure [39, 40]. Molecular dynamic (MD) simulations to model the interactions of Cn-AMP2 with a DMPC:DMPS (10:1) bilayer were undertaken. The peptide was assembled using the AMBER tools 1.5 program [41] and minimized using the GROMOS53a6 force field (2,3), which was equilibrated at room temperature in water. All simulations were performed with GROMACS software package [42, 43]. The force field for DMPS and DMPC was based on the GROMOS53a6 force fields with minor modification taken from the literature [44]. All structures were equilibrated at room temperature in water (NVT and NPT simulations) and bilayers contained 128 lipids in a box, which was $6.53 \mathrm{~nm} \times 6.53$ $\mathrm{nm}$ x $10.0 \mathrm{~nm}$ parallel to the z- axis. The GROMOS96 force field step descendent method was utilised to minimise the structure and, employing a 400 ns equilibration run at $310 \mathrm{~K}$, simulations were performed using the NPT ensemble. The Cn-AMP2 molecule was inserted into the box containing the solvated bilayer and an equilibration run was carried out for the system. The stability of association of the peptide with the surface of the DMPC:DMPS (10:1) bilayer was estimated by determining the energy required to induce Cn-AMP2 to occupy a location in the membrane interior, which was performed using the potential of mean force (PMF) facility available in Gromacs [45]. The potential energy of the system was extracted for slower pulling simulations with a pulling rate of $0.1 \AA$ /ns for 40 ns and $C n$-AMP2 was pulled in the direction parallel to the $\mathrm{Z}$ axis (5). 
Figure 2. The effects of Cn-AMP2 on the morphology of cell lines

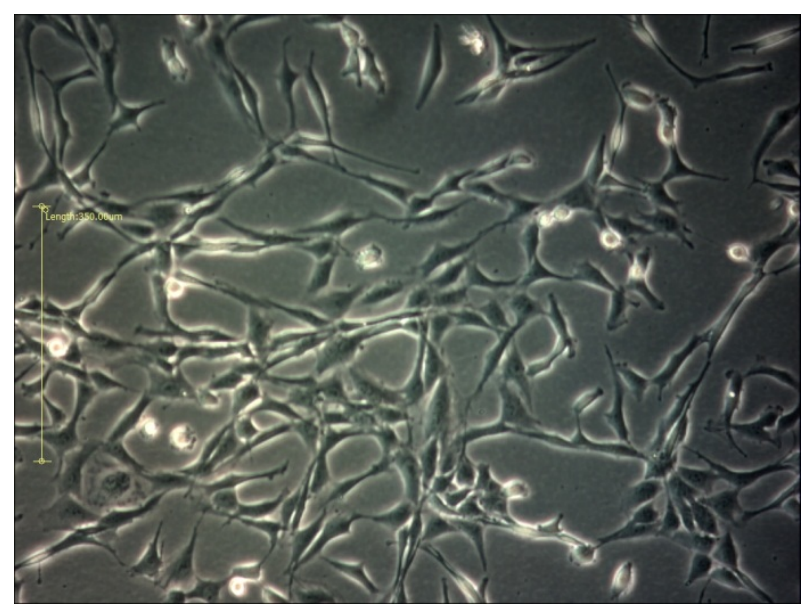

$1321 \mathrm{~N} 1$

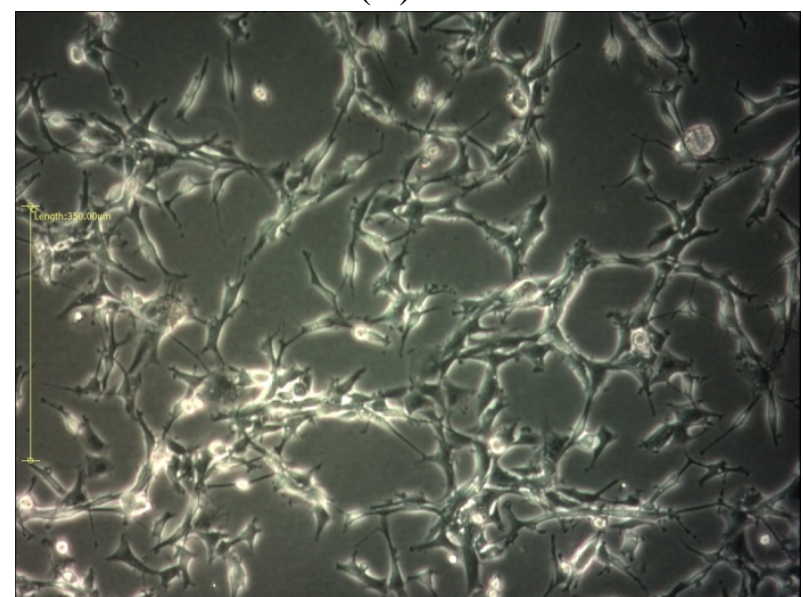

U87MG

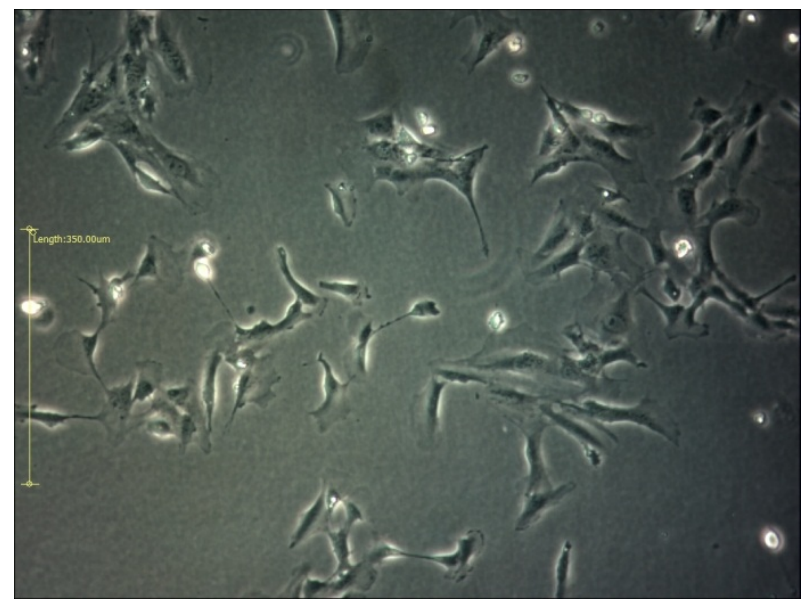

SVGp12
(A)

(E)

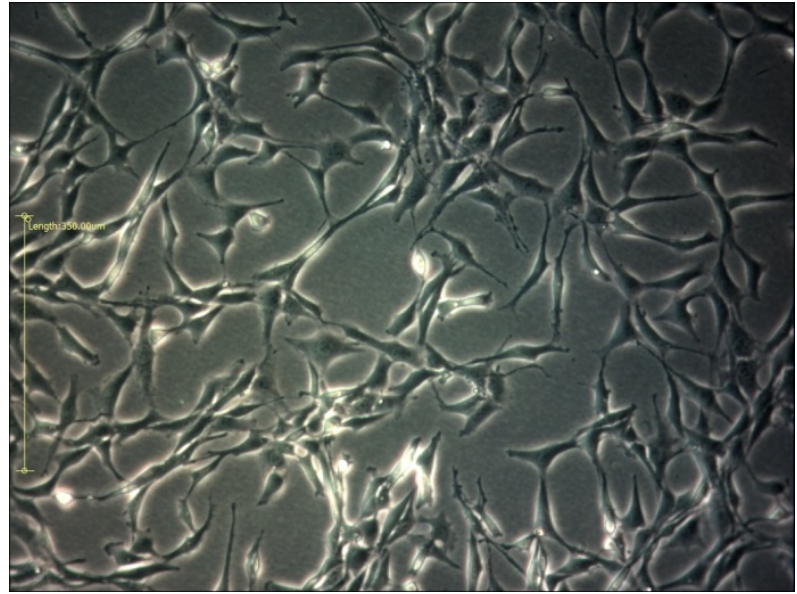

(D)

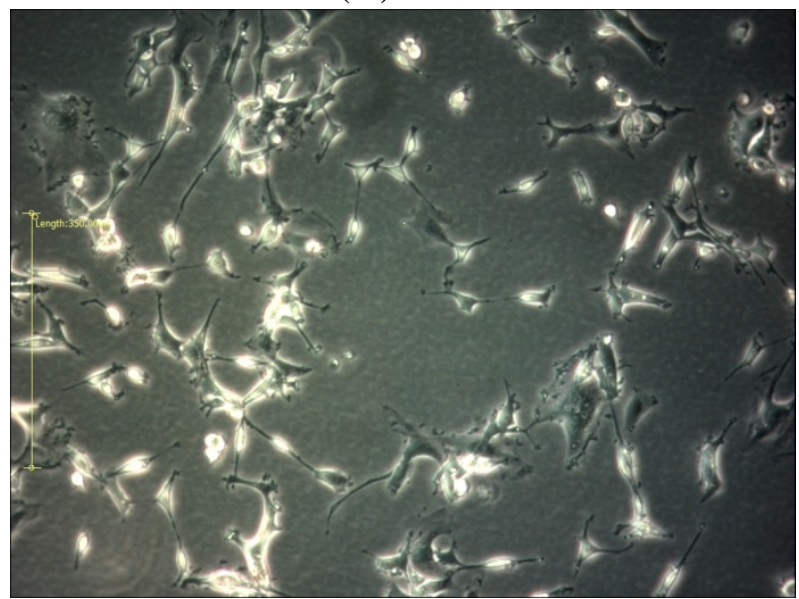

(B)

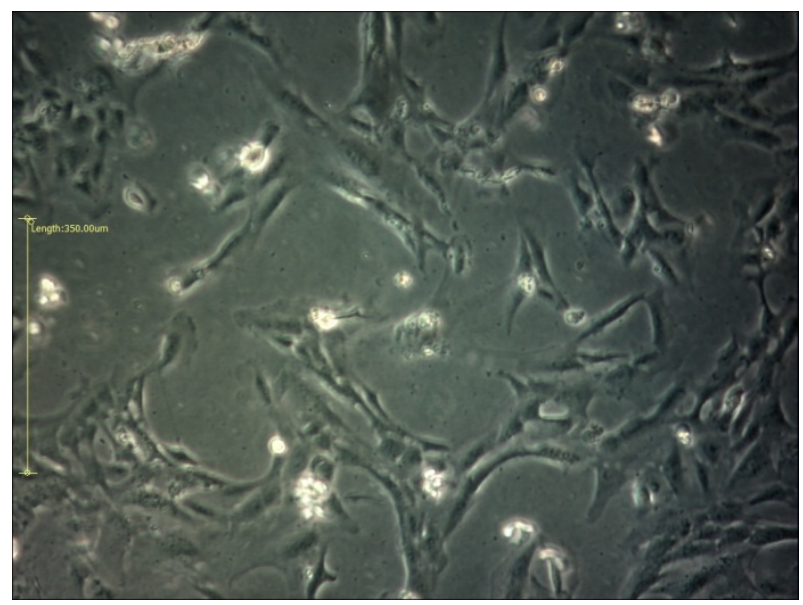

(F)

Figure 2 shows cells of the human glioma cell lines, U87MG (Figure 2A) and 1321N1 (Figure 2C), along with the non-cancerous glial cell line, SVGp12 (Figure 2E), that had been cultured in the presence of Cn-AMP2 at a peptide concentration of $2 \mathrm{mM}$. Also shown are cells of the same cell lines that had been similarly cultured but in the absence of Cn-AMP2 (Figures B, D and F). It can be clearly seen that samples treated with the peptide showed no evidence of celldeath, as indicated by a round morphology; and no sign of cell lysis, as witnessed by membrane 
fragmentation or the presence of cellular debris. All images are at a $10 \mathrm{X}$ magnification and scale bars in the images represent $350 \mu \mathrm{M}$. All cell lines were cultured as described above.

Table 1. Secondary structural contributions to $C n-\mathrm{AMP} 2$

\begin{tabular}{|c|c|c|c|}
\hline Medium & \% $\boldsymbol{\alpha}$-helix & \% $\boldsymbol{\beta}$-turns and sheet & \% Random coil \\
\hline PBS (pH 7.5) & 8 & 46 & 46 \\
\hline TFE (50\% v/v) & 4 & 47 & 49 \\
\hline DMPC & 7 & 46 & 47 \\
\hline DMPS & 3 & 49 & 47 \\
\hline DMPC / DMPS & 5 & 48 & \\
$(10: 1)$ & & & \\
\hline
\end{tabular}

The preparation of SUVS

Small unilamellar vesicles (SUVs) were constructed with a mean diameter of $0.1 \mu \mathrm{M}$ all as previously described [46]. Essentially, either pure lipids or lipid mixtures were dissolved in chloroform (5 mg ml-1), dried under $\mathrm{N}_{2}$ and further dried under vacuum overnight. The resulting lipid film was rehydrated using phosphate buffered saline [PBS; $\mathrm{pH}$ 7.5] containing $\mathrm{NaCl}(150 \mathrm{mM})$ and sonicated for an hour or until the solution was no longer turbid. To form SUVs, these solutions were then freeze-thawed $(\times 5)$ and extruded $(\times 11)$ using an Avanti polar lipid mini-extruder apparatus containing a $0.1 \mu \mathrm{m}$ polycarbonate filter (Avanti, USA).

CD structural analyses of Cn-AMP2

Cn-AMP2 (0.1 mg ml-1) was dissolved in either phosphate buffered saline [PBS; pH 7.5] or 50\% (v/v) trifluorethanol (TFE). The peptide was also dissolved in suspensions of SUVs, of either DMPC, DMPS or DMPC / DMPS (10:1), all prepared as described above, to give a peptide to lipid molar ratio of 1:100. All samples were analyzed at $20{ }^{\circ} \mathrm{C}$ on a $\mathrm{J}-815$ 
spectropolarimeter (Jasco, UK) over a wavelength range of 260 to $180 \mathrm{~nm}$, using a band width of $1 \mathrm{~nm}$ and a scan speed of $100 \mathrm{~nm} \mathrm{~min}$. For all spectra produced, the baseline acquired in the absence of Cn-AMP2 was subtracted and levels of secondary structure in the peptide estimated using Dichroweb [47-49].

\section{The membranolytic ability of Cn-AMP2}

Calcein release assay: SUVs were prepared from either DMPC, DMPS or DMPC / DMPS (10:1) all as described above except that lipid (7.5 mg) was dissolved in chloroform. After drying, the resulting lipid film was hydrated with $1 \mathrm{ml}$ of HEPES (5 mM; pH 7.5) containing calcein $(70 \mathrm{mM})$. SUVs with entrapped calcein were separated from free calcein by gel filtration using HEPES (5 mM; pH 7.5) as an elutant and a Sephadex G75 column (SIGMA), which was hydrated over-night with HEPES (20mM; pH 7.4) containing $\mathrm{NaCl}(150 \mathrm{mM})$ and EDTA (1.0 mM). The ability of Cn-AMP2 to lyse these SUVs was determined by assaying calcein release. Essentially, aliquots $(20 \mu \mathrm{l})$ of solutions containing SUVs with entrapped calcein and Cn-AMP2 at final concentrations in the range $0 \mu \mathrm{M}$ to $400 \mu \mathrm{M}$ were incubated with $2 \mathrm{ml}$ of HEPES (20 mM; pH 7.4) containing $\mathrm{NaCl}(150 \mathrm{mM})$ and EDTA (1.0 mM). The fluorescence intensity of released calcein was measured using a FP-6500 spectrofluorometer (JASCO, Tokyo Japan) with an excitation wavelength of $490 \mathrm{~nm}$ and an emission wavelength of $520 \mathrm{~nm}$. The change in fluorescence observed for calcein release when SUVs were dissolved in Triton-X100 (20 $\mu$ l) was taken to represent 100\% lysis and used to determine the percentage lysis of these SUVs by Cn-AMP2.

Haemolysis assay: The haemolytic activity of $C n$-AMP2 was investigated using a standard assay [50, 51]. Essentially, fresh human red blood cells (3 ml) were washed 3 times with phosphate buffered saline (PBS, pH 7.4) by centrifugation for 5 minutes at $1200 \times \mathrm{g}$ until the 
supernatant was clear. Washed red blood cells were resuspended in PBS to a final volume of $20 \mathrm{ml}$. Peptide solutions (10 $\mu \mathrm{l})$ were added to $190 \mu \mathrm{l}$ suspension of washed red blood cells and were incubated for $1 \mathrm{~h}$ at $37^{\circ} \mathrm{C}$. The samples were then centrifuged at $12000 \times \mathrm{g}$ for 5 minutes. The release of haemoglobin was monitored by diluting $100 \mu \mathrm{l}$ of supernatant with 900 $\mu \mathrm{l}$ PBS and measuring the absorbance at $576 \mathrm{~nm}$. For negative and positive controls, PBS buffer and $0.1 \%$ Triton $\mathrm{X}-100$ were used.

\section{Results and discussion}

There is an urgent need for new anticancer agents with novel mechanisms of action and it has been predicted that AHDPs may be an untapped source of such agents [33, 34]. Plants are known to be prolific producers of novel anticancer compounds [7, 52, 53] and the biggest single source of AHDPs with anticancer activity [35]. Accordingly, here, we have investigated the ability of Cn-AMP2, which is an AHDP found in green coconut water, derived from Cocos nucifera of the Arecaceae [36], to inactivate the human glioma cell lines, 1321N1 and U87M. It was found that increasing concentrations of $\mathrm{Cn}$-AMP2, led to progressively larger reductions in the viability of cell lines until at a peptide concentration $2.0 \mathrm{mM}$, these reductions were circa $70 \%$ (Figure 1). In contrast, across the same concentration range, the peptide induced reductions in the viability of the non-cancerous, glial cell-line, SVGp12, of circa 25\% (Figure 1). Regression analysis of these data yielded $\mathrm{IC}_{50}$ values for $C n$-AMP2 that were $1.25 \mathrm{mM}$ for the $1321 \mathrm{~N} 1$ cell line and $1.85 \mathrm{mM}$ for the U87MG cell line as compared to untreated controls. In combination, these results show that Cn-AMP2 has selective toxicity for cancer cells and comparable results were recently reported for the anticancer activity of $\mathrm{Cr}$-ACP1, which is an AHDP that was recently isolated from Cycas revolute, a plant of the Cycadaceae family [54]. 
Figure 3. CD structural analysis of Cn-AMP2

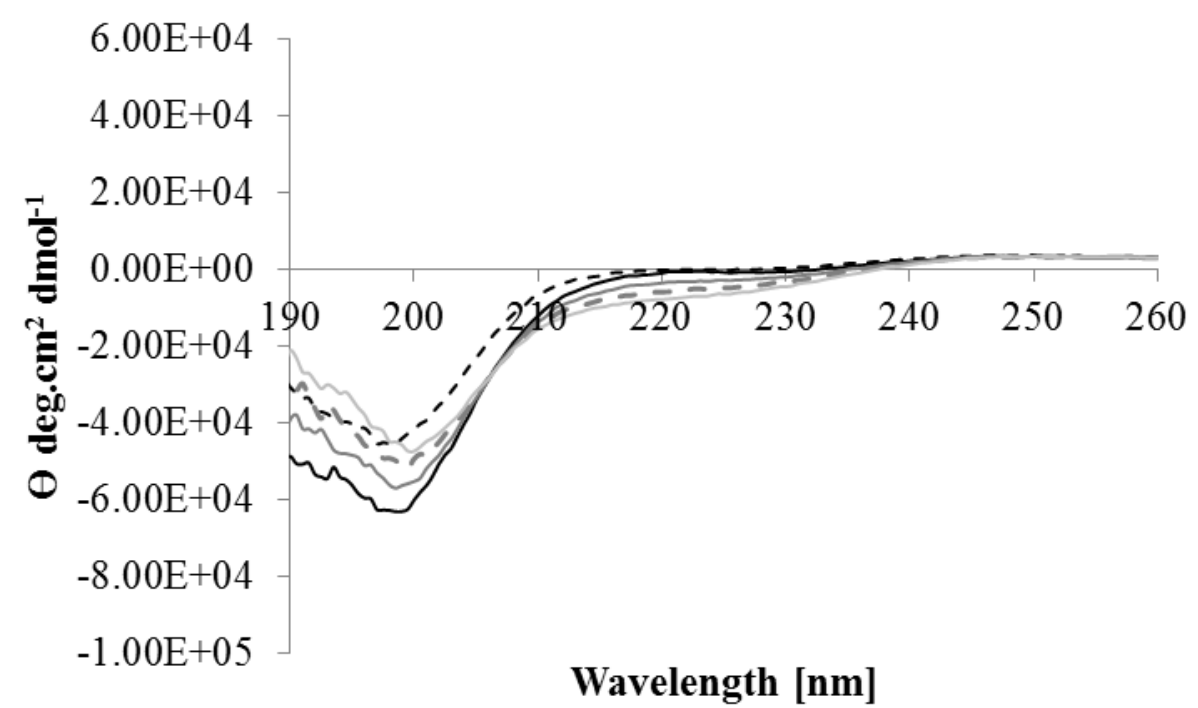

Figure 3 shows CD spectra of Cn-AMP2 in aqueous solution (black), in TFE (dotted black), which is an $\alpha$-helix promoting solvent, and in the presence of small unilamellar vesicles (SUVs), which were formed from a range of membrane lipids. These SUVs include those formed from: DMPC (grey) and DMPS (light grey) respectively, which are the major anionic and zwitterionic lipids in cancer cell membranes, and DMPC / DMPS (10:1) (dotted grey), which can be taken as representative of cancer cell membranes . Levels of secondary structure possessed by the peptide were determined from these spectra and in all cases examined, $\mathrm{Cn}$ AMP2 showed no significant propensity to adopt $\alpha$-helical structure (levels $<10 \%$ ) but rather occurred in an extended conformation, which primarily included $\beta$-type structures (levels $>$ $45 \%$ ) and random coil architecture (levels > 45\%).

The anticancer activity of all known HDPs involves interaction with the plasma membrane of these cells, leading to cell death via either membranolytic mechanisms or translocation of the peptide to attack intracellular targets [9]. Cell cultures of 1321N1 and U87MG that had been treated with Cn-AMP2 up to a concentration of $2.0 \mathrm{mM}$ showed no evidence of staining in the presence of Trypan blue, strongly suggesting that the anticancer action of the peptide does not involve membranolytic mechanisms. Reinforcing this suggestion, microscopic examination of these cultures showed that cells treated with Cn-AMP2 exhibited no significant differences in morphology to that of control cells; no evidence of celldeath, as indicated by a round morphology; and no sign of cell lysis, as witnessed by membrane fragmentation or the presence of cellular debris (Figure 2). In combination, these data suggest 
that Cn-AMP2 may be cytostatic, exerting its activity against the 1321N1 and U87MG cell lines by entering these cells and inhibiting their ability to proliferate. The anti-proliferative mechanism of the peptide was not further investigated but one possibility may be that $\mathrm{Cn}$ AMP2 induces apoptotic cell death pathways via DNA-binding as was proposed for Cr-ACP1, which is also a mono-anionic peptide that shows anti-proliferative activity [54].

A clear implication from these anticancer studies is that Cn-AMP2 has the ability to translocate cancer cell membranes and it has previously been predicted that the peptide may interact with membranes via the formation of amphiphilic $\alpha$-helical structure [36]. Many HDPs adopt this structure to facilitate partitioning into target membranes, which is reflected by their generally high values of $\left\langle\mu_{\mathrm{H}}\right\rangle$, a well-established measure of amphiphilicity [39, 40]. However, sequence analysis of Cn-AMP2 predicted that the peptide had only a very low potential to adopt $\alpha$-helical structure with a mean hydrophobic moment of $\left\langle\mu_{\mathrm{H}}\right\rangle==0.044$, which was were confirmed by CD structural analysis of the peptide. This analysis showed that Cn-AMP2 exhibited no significant propensity to adopt this form of secondary structure under any of the experimental conditions investigated (Table 2; Figure 3), particularly in the presence of SUVs formed from DMPC / DMPS (10:1), which are generally taken to mimic cancer cell membranes [55]. Rather, in the presence of these SUVs and all other cases examined, the secondary structure of Cn-AMP2 was primarily formed from $\beta$-type structures (levels $>45 \%$ ) and random coil architecture (> 45\%) (Table 2; Figure 3), suggesting that an extended conformation was the membrane interactive form of the peptide. Visual examination of the primary structure of Cn-AMP2 [36] shows that in an extended form, the C-terminal eight residues of the peptide, YFVFSVGM, form a strongly hydrophobic region, which is flanked by a short anionic segment, TES. This residue arrangement endows Cn-AMP2 with primary amphiphilicity, which has been reported for other anticancer peptides such as indolicidin [56] and is known to mediate the ability of these peptides to traverse membranes [9, 57]. 
Figure 4. A simulation of Cn-AMP2 interacting with a model cancer cell membrane.
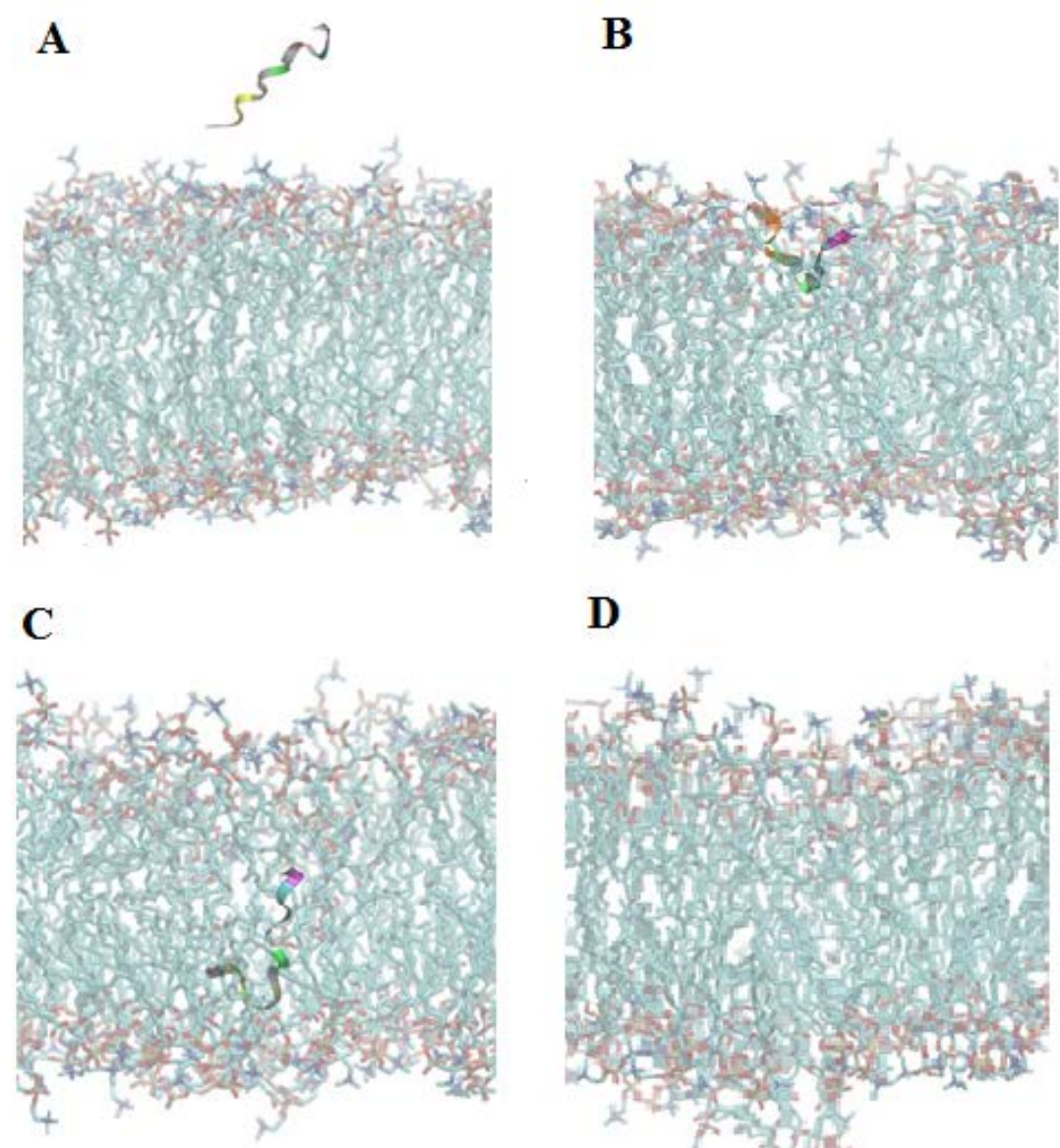

\section{D}

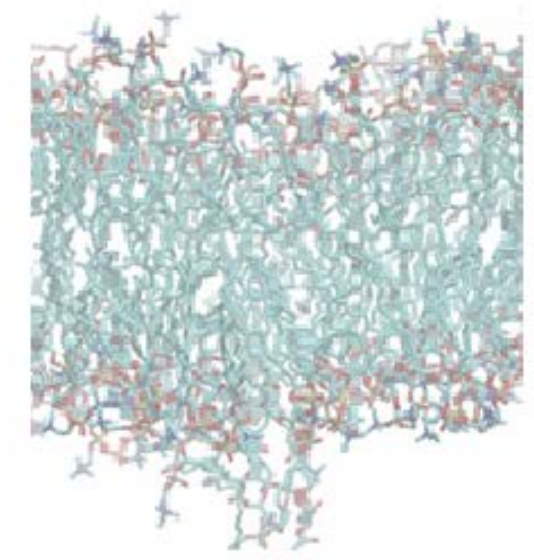

Interaction with intracellular targets that leads to the inhibition of cancer cell proliferation

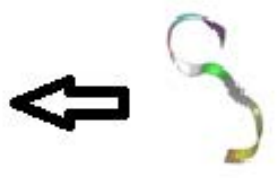
(DNA?)

$\mathbf{E}$

Figure 4 shows molecular dynamic simulations for the interaction of $C n$-AMP2 with a DMPC / DMPS (10:1) bilayer, which is a lipid composition generally taken to model cancer cell membranes [55]. In an extended conformation, Cn-AMP2 approaches the membrane surface (Figure 4A) and inserts (Figure 4B). Insertion of the peptide involves association of its anionic $\mathrm{N}$-terminal segment (TES) with positively charged moieties in the head-group region of the bilayer such as the choline group of DMPC. Complementing these electrostatic interactions, the hydrophobic C-terminal segment of Cn-AMP2 (YFVFSVGM) penetrates the apolar core region of the membrane (Figure 4B). Led by its $\mathrm{N}$-terminal region, the peptide then traverses this core region (Figure 4C) and emerges through the opposing leaflet to migrate away from the membrane surface (Figure 4D) with no significant overall perturbation of the bilayer resulting from the passage of Cn-AMP2 (Figures A to D). Based on the action of the peptide against the human glioma cell lines, $1321 \mathrm{~N} 1$ and U87MG, it is likely that emergent Cn-AMP2 attacks intracellular targets with the result that the ability of these cells to proliferate is inhibited (Figure 4E). 
The ability of Cn-AMP2 was to lyse human erythrocytes and dye-filled vesicles with lipid compositions mimetic of cancer cell membranes was investigated and no evidence of either haemoglobin or calcein release was detected, indicating that the peptide had no detectable membranolytic ability. These results are consistent with the action of the peptide on 1321N1 and U87MG cell lines and strongly support the suggestion that Cn-AMP2 may translocate cancer cell membranes to attack intracellular targets. To investigate potential mechanisms by which the peptide may translocate these membranes, molecular dynamic simulations were undertaken (Figure 4). These simulations predicted that translocation of a DMPC / DMPS (10:1) bilayer by Cn-AMP2 would involve a mechanism, which was based on the primary amphiphilicity of the peptide. As can be seen from figure 4, in an extended conformation, Cn-AMP2 approaches the membrane surface (Figure 4A) and inserts (Figure 4B). Insertion of the peptide involves association of its anionic N-terminal segment (TES) with positively charged moieties in the head-group region of the bilayer such as the choline group of DMPC. Complementing these electrostatic interactions, the hydrophobic C-terminal segment of Cn-AMP2 (YFVFSVGM) penetrates the apolar core region of the membrane (Figure 4B). Led by its N-terminal region, the peptide then traverses this core region (Figure 4C) and emerges through the opposing leaflet to migrate away from the membrane surface (Figure 4D) with no significant overall perturbation of the bilayer resulting from the passage of Cn-AMP2 (Figures A to D). Based on the action of the peptide against the human glioma cell lines, 1321N1 and U87MG, it is likely that emergent Cn-AMP2 then attacks intracellular targets such as DNA with the result that the ability of these cells to proliferate is inhibited (Figure 4E).

In summary, this study has shown that Cn-AMP2 has activity against several human glioma, expanding the small repertoire of AHDPs known to possess anticancer activity [33, 34]. The action of Cn-AMP2 against these cancer cells appears to involve anti-proliferative 
mechanisms, which result from the ability of the peptide to translocate cancer cell membranes through a hydrophobicity-driven mechanism. Use of this mechanism would seem to reflect the fact that $C$-AMP2 is devoid of cationic residues and therefore lacks the capacity to engage in the electrostatically-driven mechanisms of cancer cell targeting utilised by most HDPs [9]. However, this lack of cationic residues could also give Cn-AMP2 an advantage over CHDPs with anticancer action whose possession of lysine and arginine residues makes them highly susceptible to degradation by human proteases [20,58]. Clearly, the levels of Cn-AMP2 shown here to be necessary for anticancer activity are prohibitive for the therapeutic application of the peptide. However, given the problems due to the increasing prevalence of cancer on a global scale and the urgent need for solutions, we suggest that Cn-AMP2 may represent a template for the development of novel HDPs with clinically useful, anticancer activity.

\section{References}

1. Bray, F., Jemal, A., Grey, N., Ferlay, J., Forman, D., Global cancer transitions according to the Human Development Index (2008-2030): a population-based study. Lancet Oncology, 2012. 13(8): 790-801. DOI: 10.1016/s1470-2045(12)70211-5.

2. Martin Sabroso, C.Torres-Suarez, A.I., Objective: tumor. Strategies of drug targeting at the tumor mass level. Clinical \& Translational Oncology, 2014. 16(1): 1-10. DOI: 10.1007/s12094-013-1075-4.

3. Saraswathy, M.Gong, S., Different strategies to overcome multidrug resistance in cancer. Biotechnology Advances, 2013. 31(8): 1397-1407. DOI: 10.1016/j.biotechadv.2013.06.004.

4. Urruticoechea, A., Alemany, R., Balart, J., Villanueva, A., Vinals, F., Capella, G., Recent Advances in Cancer Therapy: An Overview. Current Pharmaceutical Design, 2010. 16(1): 3-10.

5. $\quad$ Cragg, G.M., Grothaus, P.G., Newman, D.J., Impact of Natural Products on Developing New Anti-Cancer Agents. Chemical Reviews, 2009. 109(7): 3012-3043. DOI: 10.1021/cr900019j.

6. Balderas-Renteria, I., Gonzalez-Barranco, P., Garcia, A., Banik, B.K., Rivera, G., Anticancer Drug Design Using Scaffolds of beta-Lactams, Sulfonamides, Quinoline, Quinoxaline and Natural Products. Drugs Advances in Clinical Trials. Current Medicinal Chemistry, 2012. 19(26): 4377-4398.

7. Cragg, G.M.Newman, D.J., Natural products: A continuing source of novel drug leads. Biochimica Et Biophysica Acta-General Subjects, 2013. 1830(6): 3670-3695. DOI: 10.1016/j.bbagen.2013.02.008. 
8. Newman, D.J.Cragg, G.M., Natural Products As Sources of New Drugs over the 30 Years from 1981 to 2010. Journal of Natural Products, 2012. 75(3): 311-335. DOI: 10.1021/np200906s.

9. Harris, F., Dennison, S.R., Singh, J., Phoenix, D.A., On the selectivity and efficacy of defense peptides with respect to cancer cells. Medicinal Research Reviews, 2013. 33(1): 190-234. DOI: 10.1002/med.20252.

10. Dennison, S.R., Whittaker, M., Harris, F., Phoenix, D.A., Anticancer alpha-helical peptides and structure/function relationships underpinning their interactions with tumour cell membranes. Curr Protein Pept Sci, 2006. 7(6): 487-499.

11. Gaspar, D., Veiga, A.S., Castanho, M.R.B., From antimicrobial to anticancer peptides. A review. Frontiers in Microbiology, 2013. 4. DOI: 10.3389/fmicb.2013.00294.

12. Pasupuleti, M., Schmidtchen, A., Malmsten, M., Antimicrobial peptides: key components of the innate immune system. Critical Reviews in Biotechnology, 2012. 32(2): 143-171. DOI: 10.3109/07388551.2011.594423.

13. Phoenix, D.A., Dennison, S.R., Harris, F., Antimicrobial Peptides: Their History, Evolution, and Functional Promiscuity, in Antimicrobial Peptides Wiley-VCH Verlag GmbH \& Co. KGaA. 2013, pp. 1-37.

14. Li, Y., Xiang, Q., Zhang, Q., Huang, Y., Su, Z., Overview on the recent study of antimicrobial peptides: Origins, functions, relative mechanisms and application. Peptides, 2012. 37(2): 207-215. DOI: 10.1016/j.peptides.2012.07.001.

15. Wang, G., Li, X., Wang, Z., APD2: the updated antimicrobial peptide database and its application in peptide design. Nucleic Acids Research, 2009. 37: D933-D937. DOI: 10.1093/nar/gkn823.

16. Wang, G., Li, X., Zasloff, M., A Database View of Naturally Occurring Antimicrobial Peptides: Nomenclature, Classification and Amino Acid Sequence Analysis. Antimicrobial Peptides: Discovery, Design and Novel Therapeutic Strategies, ed. G. Wang.2010

17. Dennison, S.R., Harris, F., Phoenix, D.A., Models for the membrane interactions of antimicrobial peptides, in Antimicrobial peptides, D.A. Phoenix, S.R. Dennison, and F. Harris, Editors Wiley. 2013.

18. Nicolas, P., Multifunctional host defense peptides: intracellular-targeting antimicrobial peptides. Febs J., 2009. 276(22): 6483-6496. DOI: 10.1111/j.1742-4658.2009.07359.x.

19. Cho, J.H., Sung, B.H., Kim, S.C., Buforins: Histone H2A-derived antimicrobial peptides from toad stomach. Biochim. Biophys. Acta-Biomembr., 2009. 1788(8): 15641569. DOI: 10.1016/j.bbamem.2008.10.025.

20. Riedl, S., Zweytick, D., Lohner, K., Membrane-active host defense peptides Challenges and perspectives for the development of novel anticancer drugs. Chem. Phys. Lipids, 2011. 164(8): 766-781. DOI: 10.1016/j.chemphyslip.2011.09.004.

21. Al-Benna, S., Shai, Y., Jacobsen, F., Steinstraesser, L., Oncolytic Activities of Host Defense Peptides. Int. J. Mol. Sci., 2011. 12(11): 8027-8051. DOI: 10.3390/ijms12118027.

22. Dennison, S.R., Harris, F., Phoenix, D.A., Are oblique orientated alpha-helices used by antimicrobial peptides for membrane invasion? Protein Pept. Lett., 2005. 12(1): 27-29. DOI: $10.2174 / 0929866053406039$.

23. Harris, F., Dennison, S.R., Phoenix, D.A., Aberrant action of amyloidogenic host defense peptides: a new paradigm to investigate neurodegenerative disorders? Faseb Journal, 2012. 26(5): 1776-1781. DOI: 10.1096/fj.11-199208.

24. Gotay, C.C., Cancer prevention: major initiatives and looking into the future. Expert Rev. Pharmacoecon. Outcomes Res., 2010. 10(2): 143-154. DOI: 10.1586/erp.10.9. 
25. Hogberg, L.D., Heddini, A., Cars, O., The global need for effective antibiotics: challenges and recent advances. Trends Pharmacol. Sci., 2010. 31(11): 509-515. DOI: 10.1016/j.tips.2010.08.002.

26. Harris, F.Pierpoint, L., Photodynamic therapy based on 5-aminolevulinic acid and its use as an antimicrobial Agent. Medicinal Research Reviews, 2012. 32(6): 1292-1327. DOI: 10.1002/med.20251.

27. Avner, B.S., Fialho, A.M., Chakrabarty, A.M., Overcoming drug resistance in multidrug resistant cancers and microorganisms: a conceptual framework. Bioengineered, 2012. 3(5): 262-270. DOI: 10.4161/bioe.21130.

28. Shekhar, M.P.V., Drug Resistance: Challenges to Effective Therapy. Curr. Cancer Drug Targets, 2011. 11(5): 613-623.

29. Yeung, A.T.Y., Gellatly, S.L., Hancock, R.E.W., Multifunctional cationic host defence peptides and their clinical applications. Cell. Mol. Life Sci., 2011. 68(13): 2161-2176. DOI: 10.1007/s00018-011-0710-X.

30. Rajanbabu, V.Chen, J.Y., Applications of antimicrobial peptides from fish and perspectives for the future. Peptides, 2011. 32(2): 415-420. DOI: 10.1016/j.peptides.2010.11.005.

31. Varadhachary, A., Barsky, R., Pericle, F., Petrak, K., Wang, Y., Lactoferrin in the treatment of malignant neoplasms and other hyperproliferative diseases, 2012, Agennix Incorporated.

32. Tsuda, H., Kozu, T., Iinuma, G., Ohashi, Y., Saito, Y., Saito, D., Akasu, T., Alexander, D.B., Futakuchi, M., Fukamachi, K., Xu, J., Kakizoe, T., Iigo, M., Cancer prevention by bovine lactoferrin: from animal studies to human trial. Biometals, 2010. 23(3): 399409. DOI: $10.1007 / \mathrm{s} 10534-010-9331-3$.

33. Harris, F., Dennison, S., Phoenix, D., Anionic Antimicrobial Peptides from Eukaryotic Organisms and their Mechanisms of Action. Current Chemical Biology, 2011. 5(2): 142-153.

34. Harris, F., Dennison, S.R., Phoenix, D.A., Anionic Antimicrobial Peptides from Eukaryotic Organisms. Current Protein \& Peptide Science, 2009. 10(6): 585-606.

35. Prabhu, S., Dennison, S.R., Lea, B., Snape, T.J., Nicholl, I.D., Radecka, I., Harris, F., Anionic Antimicrobial and Anticancer Peptides from Plants. Critical Reviews in Plant Sciences, 2013. 32(5): 303-320. DOI: 10.1080/07352689.2013.773238.

36. Mandal, S.M., Dey, S., Mandal, M., Sarkar, S., Maria-Neto, S., Franco, O.L., Identification and structural insights of three novel antimicrobial peptides isolated from green coconut water. Peptides, 2009. 30(4): 633-637.

37. Prabhu, S., Effects of novel compounds in an in vitro chemosensitivity system for glioma treatment, 2012, University of Central Lancashire: UK.

38. Dawson, T.P., Iyer, R.V., Lea, R.W., Roberts, P., Harris, F., Ashton, K., Golash, A., Davis, C.H.G., The MTS vs. the ATP assay for in vitro chemosensitivity testing of primary glioma tumour culture. Neuropathology and Applied Neurobiology, 2010. 36(6): 564-567. DOI: 10.1111/j.1365-2990.2010.01096.x.

39. Phoenix, D.A.Harris, F., The hydrophobic moment and its use in the classification of amphiphilic structures (Review). Molecular Membrane Biology, 2002. 19(1): 1-10. DOI: $10.1080 / 09687680110103631$.

40. Phoenix, D.A., Harris, F., Daman, O.A., Wallace, J., The prediction of amphiphilic alpha-helices. Current Protein \& Peptide Science, 2002. 3(2): 201-221. DOI: $10.2174 / 1389203024605368$.

41. AMBER. http:/ambermd.org. 2010. 
42. Hess, B., Kutzner, C., van der Spoel, D., Lindahl, E., GROMACS 4: Algorithms for Highly Efficient, Load-Balanced, and Scalable Molecular Simulation. Journal of Chemical Theory and Computation, 2008. 4(3): 435-447. DOI: 10.1021/ct700301q.

43. Van der Spoel, D., Lindahl, E., Hess, B., Groenhof, G., Mark, A.E., Berendsen, H.J.C., GROMACS: Fast, flexible, and free. Journal of Computational Chemistry, 2005. 26(16): 1701-1718. DOI: 10.1002/jcc.20291.

44. Malde, A.K., Zuo, L., Breeze, M., Stroet, M., Poger, D., Nair, P.C., Oostenbrink, C., Mark, A.E., An Automated Force Field Topology Builder (ATB) and Repository: Version 1.0. Journal of Chemical Theory and Computation, 2011. 7(12): 4026-4037. DOI: $10.1021 / \mathrm{ct} 200196 \mathrm{~m}$.

45. Lumb, C.N., He, J., Xue, Y., Stansfeld, P.J., Stahelin, R.V., Kutateladze, T.G., Sansom, M.S.P., Biophysical and Computational Studies of Membrane Penetration by the GRP1 Pleckstrin Homology Domain. Structure, 2011. 19(9): 1338-1346. DOI: 10.1016/j.str.2011.04.010.

46. Wall, J., Golding, C.A., Van Veen, M., O'Shea, P., The use of fluoresceinphosphatidylethanolamine (FPE) as a real-time probe for peptide-membrane interactions. Mol Membr Biol, 1995. 12(2): 183-192.

47. Whitmore, L.Wallace, B.A., DICHROWEB, an online server for protein secondary structure analyses from circular dichroism spectroscopic data. Nucleic Acids Research, 2004. 32: W668-W673. DOI: 10.1093/nar/gkh371.

48. Whitmore, L.Wallace, B.A., Protein secondary structure analyses from circular dichroism spectroscopy: Methods and reference databases. Biopolymers, 2008. 89(5): 392-400. DOI: 10.1002/bip.20853.

49. Whitmore, L., Woollett, B., Miles, A.J., Janes, R.W., Wallace, B.A., The Protein Circular Dichroism Data Bank, A Web-Based Site for Access to Circular Dichroism Spectroscopic Data. Structure, 2010. 18(10): 1267-1269. DOI: 10.1016/j.str.2010.08.008.

50. Oh, D., Shin, S.Y., Lee, S., Kang, J.H., Kim, S.D., Ryu, P.D., Hahm, K.S., Kim, Y., Role of the hinge region and the tryptophan residue in the synthetic antimicrobial peptides, cecropin A(1-8)-magainin 2(1-12) and its analogues, on their antibiotic activities and structures. Biochemistry, 2000. 39(39): 11855-11864. DOI: bi000453g [pii].

51. Song, Y.M., Park, Y., Lim, S.S., Yang, S.T., Woo, E.R., Park, I.S., Lee, J.S., Kim, J.I., Hahm, K.S., Kim, Y., Shin, S.Y., Cell selectivity and mechanism of action of antimicrobial model peptides containing peptoid residues. Biochemistry, 2005. 44(36): 12094-12106. DOI: 10.1021/bi050765p.

52. Khazir, J., Mir, B.A., Pilcher, L., Riley, D.L., Role of plants in anticancer drug discovery. Phytochemistry Letters, 2014. 7: 173-181. DOI: 10.1016/j.phytol.2013.11.010.

53. Unnati, S., Ripal, S., Sanjeev, A., Niyati, A., Novel anticancer agents from plant sources. Chinese Journal of Natural Medicines, 2013. 11(1): 16-23.

54. Mandal, S.M., Migliolo, L., Das, S., Mandal, M., Franco, O.L., Hazra, T.K., Identification and characterization of a bactericidal and proapoptotic peptide from cycas revoluta seeds with DNA binding properties. Journal of Cellular Biochemistry, 2012. 113(1): 184-193. DOI: 10.1002/jcb.23343.

55. Dennison, S.R., Harris, F., Phoenix, D.A., The interactions of aurein 1.2 with cancer cell membranes. Biophysical Chemistry, 2007. 127(1-2): 78-83. DOI: 10.1016/j.bpc.2006.12.009. 
56. Dennison, S.R., Wallace, J., Harris, F., Phoenix, D.A., Amphiphilic alpha-helical antimicrobial peptides and their structure/function relationships. Protein Pept. Lett., 2005. 12(1): 31-39. DOI: 10.2174/0929866053406084.

57. Chan, D.I., Prenner, E.J., Vogel, H.J., Tryptophan- and arginine-rich antimicrobial peptides: Structures and mechanisms of action. Biochim. Biophys. Acta-Biomembr., 2006. 1758(9): 1184-1202. DOI: 10.1016/j.bbamem.2006.04.006.

58. Cho, J.H.Kim, S.C., Non-membrane Targets of Antimicrobial Peptides: Novel Therapeutic Opportunities? Antimicrobial Peptides: Discovery, Design and Novel Therapeutic Strategies, ed. G. Wang.2010 